\section{A Protocol for Authentication of Paintings}

Walter C. McCrone, McCrone Research Institute and Eugene Markowski, Trinity College

Strictly speaking, it is impossible to authenticate any painting to the extent of naming the artist who produced that object. One can only increase the likelihood thereof. In one celebrated case I felt I had fully proved that Manets palette had indeed been used to paint a particular painting but a "scholar" on whose reaction the art world depends for final acceptance of authenticity only said "someone" could have borrowed Manets palette one fine day and painted that picture. In a second celebrated case I was able to prove, but not convince, the world that a particular painting (Shroud of Turin) was, in fact, a painting and not an artifact produced by some other mysterious means, e.g., some sort of photographic process or resurrection itself.

We can only suggest the ways and means of increasing the likelihood of authenticity in terms of a particular artist's effort. This includes a cooperative approach by a group of experts: experts in the composition and dating of the physical components, i.e., pigments, medium, and support of the painting, scholars trained in art history investigators able to develop the provenance for that painting and stylists trained in the study of the attributed artist's painting techniques and style(s). The idea of authenticity extends from authenticity of the painting to authenticity of the experts themselves. They must be proven (and recognized as proven) experts in one or more of the areas of science and scholarship involved in evaluating authenticity.

There is a basic difference between the scientific contribution to the question of authenticity of an object and that of the scholars. Carbon-dating and pigment identification techniques answer a "Yes or No" question. Either they yield a date within the time of an attributed artist or they do not. On the other hand, the contributions of the scholars are still subjective and we often find such experts divided on the subject of authenticity of a given painting.

\section{Introduction}

There is a need for an organization, recognized by the art world, charged with the task of evaluating claims of authenticated-artist paintings. If this panel then states that the evidence of the experts has sufficiently proved the likelihood that a given painting is authentic then their published conclusion to that effect should be accepted by the art world and that painting is authentic.

The only paintings I would bet my last dollar on being authentic would be "The Last Supper" by Leonardo or Michelangelo's Sistine Chapel murals. Any paintings on canvas, wood or other portable surfaces are impossible for anyone to authenticate with absolute certainty. The experience of the Rembrandt Committee during the past few years in deauthenticating dozens of previously "authentic" Rembrandts is a case in point. We can only build up positive evidence in favor of authenticity until recognized art experts concede a given painting is authentic. Even then the accolade of authenticity is an opinion and many such have been discredited by subsequent experts.

To have a chance of being acknowledged as authentic requires a body of evidence sufficient to reduce doubts to the point they can be ignored. This requires significant convincing evidence based on scientific analyses of composition of all painting components (pigments, medium, and support). Equally important are the opinions of art scholars experienced in the iconographic aspects and style characteristics of the artist's works during different periods of their career. And finally, a convincing provenance for that painting must be determined to the degree possible. Unfortunately, it is impossible to prove to the satisfaction of everyone that any painting is authentic. A confirmed skeptic can always find some reason why any painting cannot be authentic. I can cite two such examples.

I once worked on a painting "The Infanta Marie Marguerite", a painting alleged to be a lost copy of a Valasquez painting in the Louvre by Edouard Manet about $1860^{\circ}$. I found that the pigments not only matched Manet's known palette of that period but amazingly to me, it contained very rare variants of three of these pigments I had never seen before. They were cobalt blue, lead white and vermilion; all known to, and used by, Manet but not usually in the variant forms I found in The Infanta. The cobalt blue had a uniquely low refractive index. The lead white was $\mathrm{Pb}\left(\mathrm{CO}_{3}\right)$ rather than the usual $\mathrm{Pb}\left(\mathrm{CO}_{3}\right) \mathrm{Pb}(\mathrm{OH})_{2}$, and the vermilion was unusually pure in terms of trace elements.

Two paintings "known" to have been painted by Manet about $1860^{*}$ were then analyzed and found to have these same three variant pigments. In addition, individual lead white pigment crystals from both the Infanta and the Ballet Espagnol were analyzed quantitatively for trace metals. Both contain the same nine trace metals in closely similar percentages; this can only mean they have a common source. I concluded those three pigments in three different paintings could not be more similar if they had been squeezed from the same tubes of paint. I couldn't imagine any better proof of authenticity of the Infanta Marie Marguerite than that, but a scholar whose opinion we sought only said someone could have borrowed Manet's palette and painted the Infanta.

Another acutely frustrating experience involved a grisaille painting on linen done with red ochre and vermilion pigments in a gelatin medium ${ }^{2}$. There can be no doubt about that conclusion but a vocal body of dissenters state in no uncertain terms that the image is blood and no pigments are present. Obviously, opinions are more important than facts in some authenticity studies, especially religious relics.

There is a great need for a better understanding of what constitutes authenticity and for a recognized panel of experts capable of evaluating claims of authenticity and able to present a "certificate" of authenticity that would be accepted by the art world. An organization I believe well qualified for such a responsibility is IFAR, the International Foundation for Art Research in Manhattan. They are best known for their Stolen Art Alert, a record of stolen art and efforts to recover such. They also accept individual authenticity problems and are very competent in evaluating, and helping to establish, authenticity.

Many, if not most, of us are familiar with IFAR Reports a publication that publicizes stolen art and makes authenticity studies. When IFAR was established in 1969 by a group of highly qualified and highly regarded personages in the art world their interests were principally in publicizing art thefts. As time went on their interest, reflecting the interests of the Executive Directors: Constance Lowenthal and, currently, Sharon Flescher gradually changed to more emphasis on authentication and less on stolen art. Recent articles by Alexander Katlan and Sharon Flescher

\section{Continued on page 10}

* Ballet Espagnol, Philips Gallery, Washington, D.C. and La Verscuse: La Femme à la Cruche, Ordrupgaard Collection, Copenhagen 


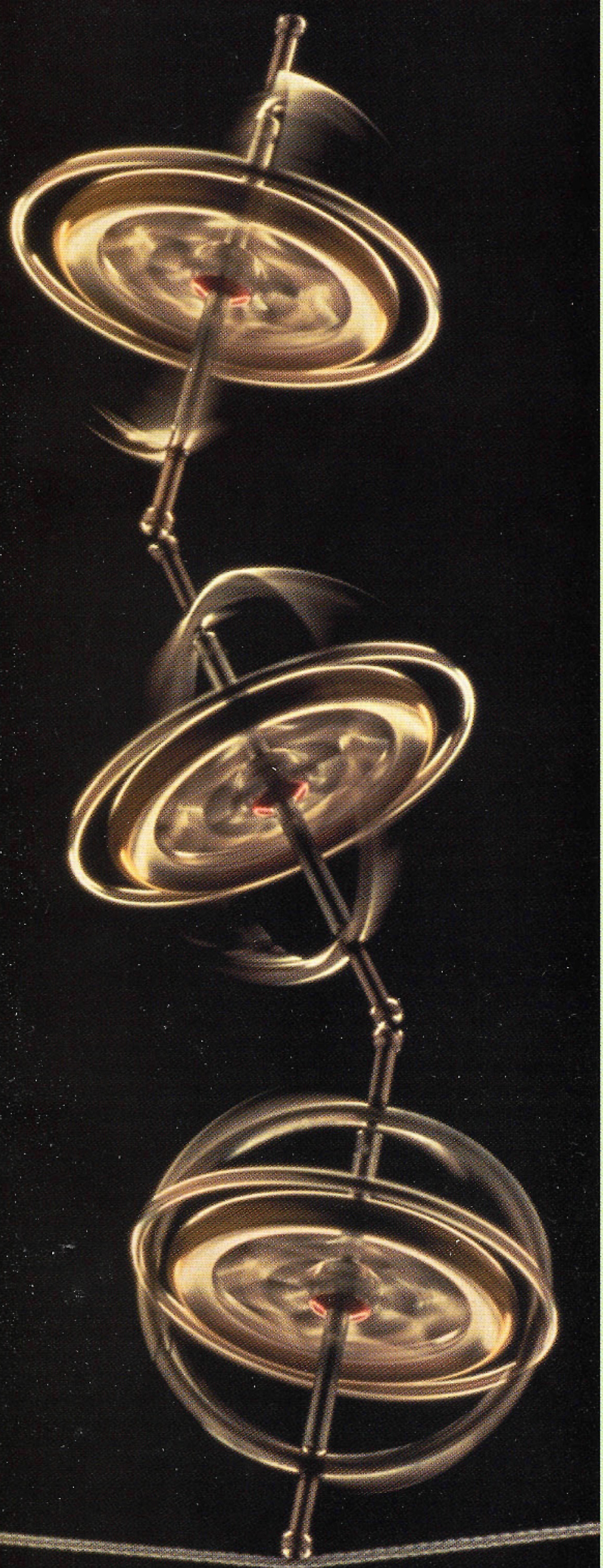

\section{Getting All Your Detectors Working Together Can Be A Tough Balancing Act. \\ That's Where Emispec Comes In.}

If balancing all components of your detectors has your head spinning, you should be talking to us.

You see, at Emispec Systems, Inc., we approach data acquisition differently. Instead of creating systems targeting one detector, we focus on integration. This concept can be applied equally to new and existing electron microscope installations. Core acquisition capabilities of our products include:

- Digital scanning for STEM.

- Digital EDX acquisition and analysis.

- EELS acquisition and analysis.

- CCD and TV imaging.

Integrated microscope control, imaging and spectroscopy allows automation of demanding experiments, such as spectrum imaging. Emispec enhances these capabilities with extensive on-line and off-line processing.

To find out how Emispec can help your lab keep in balance, visit our Web site today at www.emispec.com. See why we are fast becoming the leader in microscope detector technology solutions.

\section{Emispec}

Emispec Systems, Inc

2409 South Rural Road, Suite D

Tempe, Arizona 85282 USA

Phone: 480.894 .6443 - Fax: 480.894 .6458 Web: wuw.emispec.com

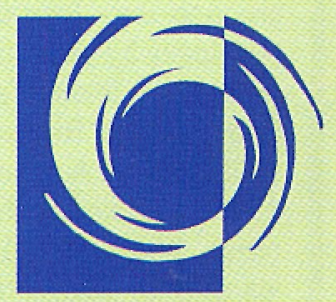

thinking beyond the box ${ }^{\mathrm{TM}}$ 


\section{A Protocol for Authentication of Paintings Continued from page 8}

(with Adrian Sudhaler) are excellent examples of IFAR's interest and ability in authentication research. As of 1998, IFAR took on a new life with the retirement of Constance Lowenthal. Her ideal replacement is Sharon Flescher, and IFAR Reports is now a more formal quarterly IFAR Journal. Virgilia Pancoast, I am pleased to see, is still Consultant, Authentication Services. The Journal now publishes formal papers.

With world-wide contacts and a very high reputation, IFAR has the ability to fill a real gap in authentication studies. For too long, the subjective viewpoints of many scholars have left many works of art in limbo, neither accepted nor unaccepted as authentic. I believe IFAR could evaluate existing claims of authenticity, advise owners of steps they should take and perform additional work to test those claims and produce a carefully considered opinion that can, as time goes on, be increasingly accepted as a final verdict. I dearly hope that will happen. My interest in authentication stems from 30 years of studying paintings scientifically. This includes pigment, medium and support identification using polarized light microscopy, fourier transform infrared absorption, energy dispersive $x$-ray analysis, infrared and ultraviolet light examination, $\mathrm{x}$-radiography and, when helpful, dendrochronology and carbon dating. These methods enable us to evaluate attribution of the painting to a particular artist. The presence of prussian blue (1704) in a Rembrandt precludes that attribution. I can conclude with certainty that a painting could not have been done by the attributed artist but I can never conclude an attribution is correct. I always recommend these scientific tests be done first because they are far less costly than the investigations of provenance, iconography, style, etc., and because about $80 \%$ of the paintings I have studied fail the scientific tests and the then-useless expensive connoisseur studies are avoided (unless the owner wishes to establish a different attribution).

I have reported the $20 \%$ of paintings I pass by my scientific tests as possibly correctly attributed. I usually state that I found no scientific result to render the attribution false. I occasionally feel pretty sure the attribution is correct. The Infanta Marie Marguerite by Manet because of the unique pigments or Harringtons Christ and the Doctors by Leonardo because of the connoisseurship results. Still no collector whose paintings passed my tests has been able to gain acceptance of their attribution by the scholars. Many have spent years and many dollars in further investigations without encouragement, much less success and sale. Their paintings are in limbo. There is unfortunately little mutual understanding or respect between the scientists and the scholars. To help correct this state of affairs I set up a Paintings Authentication Committee (PAC) several years ago hopefully to gain cooperation between both groups in the study of authentication. A major meeting of this group in San Jose last fall was well attended and 21 papers, principally by scientists, are included in Proceedings published as a book titled "Fakebusters". It can be obtained from the Senior Editor Richard J. Weiss, 4 Lawson Street, Avon, MA 02322-1708. A second meeting was held on 20-21 September 1999 in Boston. My thinking has evolved for the need for a group, hopefully IFAR, to finally bring the authentication studies of both scientists and scholars to a mutual conclusionsones that would be accepted by the artworld and world of limbo

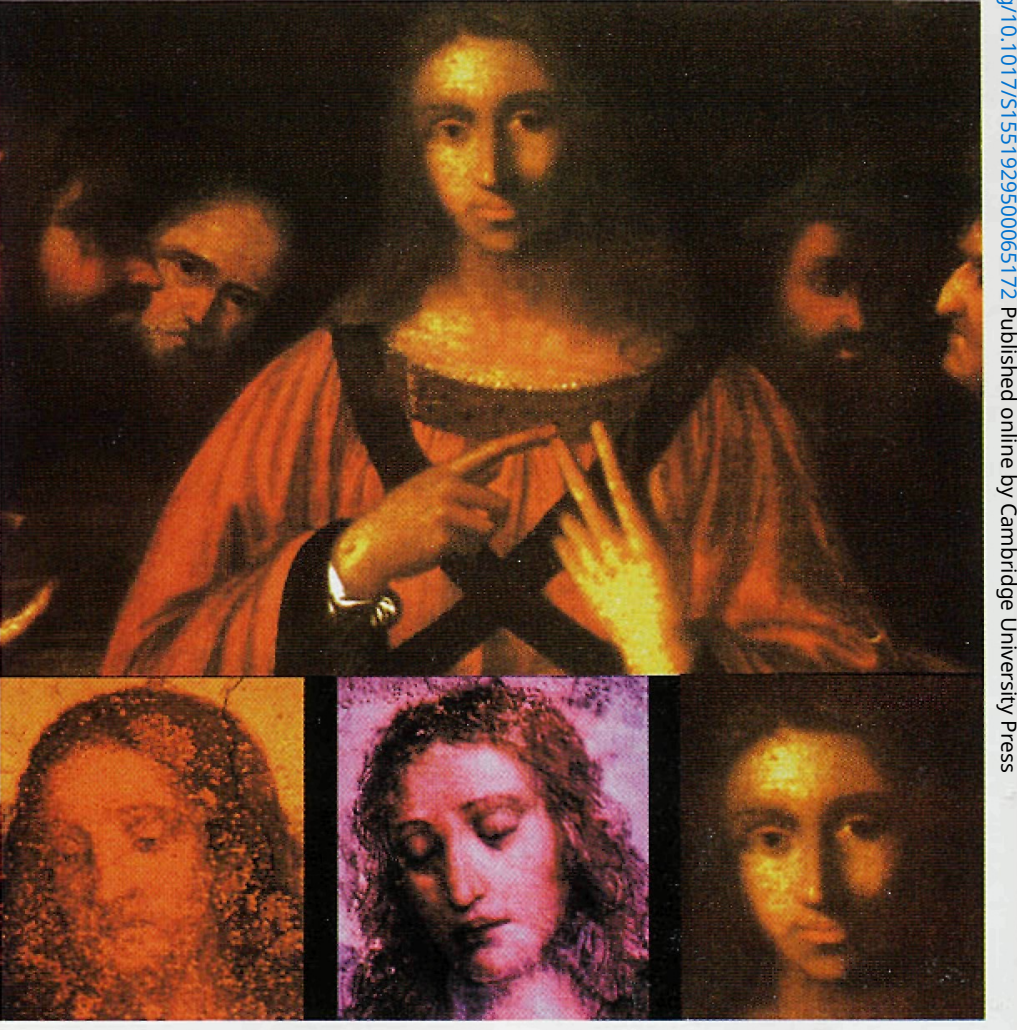

may then lose some of its many inhabitants.

Back to my "Protocol", I would like to present, as an example of the protocol for authenticating paintings, John Harrington's Christ Among the Doctors. John Harrington possesses a remarkable set of qualities: an avid interest in art, an eye for quality, and an ability, most historians would envy, of being able to investigate and establish a credible provenance for authentic paintings. A pretty complete coverage of what was then Harringtons 12-year authentication effort has been published ${ }^{3}$.

Since that publication at least two additional art scholars have studied Christ Among the Doctors and concluded it to be a longlost Leonardo painting as believed by John Harrington. Klára Garas of Budapest has a long and important background in the arts. Starting with a Degree in "History of Art and Archeology" from the University of Budapest, she went on to become Assistant Curator, Curator and finally Director of the Museum of Fine Arts in Budapest (1964-1984). She is a member of the Hungarian Academy of Sciences and has published more than 100 articles in Art magazines and scientific journals; at least 10 books including: Paintings in Hungary in the 17th Century, followed by the same title but in the 18th Century, Venetian Paintings of the 18th Century, and Italian Portraits of the Renaissance. An as-yet unpublished book covers in detail the paintings of Giorgione.

Her study of Christ Among the Doctors-Harrington led to strong evidence that this painting had been owned by the noted Italian Martinelli family, since the 16th Century. The Martinelli family was then, and later, closely associated with the theatre and the arts in Italy. John Harrington purchased Christ Among the Doctors in 1984 from a present member of that family. Klára's conclusion after her historical study was that Leonardo painted John Harrington's picture.

Another well-known scholar, Professor of Art History, Eugene Markowski, of Trinity College in Washington D.C. has made an independent detailed study of Christ Among the Doctors-Harrington and his critical analysis follows: 


\section{The Iconography}

A. Christ's Vestments: The cloth bands that criss-cross the Christ figure in Christ Among the Doctors are a representation of the liturgical stole worn as part of the priest's liturgical vestments during the time of Christ. During this period the stole represented the priest's authority as teacher, or presider, one who led the congregation in religious ceremonies. For priests in the Roman Catholic Church, the stole was worn outside the other vestments; by Vatican II and until recently, the stole was worn under the other vestments. Presently, the stole is worn over the priest's shoulders, and hangs down alongside the arms.

1. Vestment color: The color of the vestment under the stole worn by the Christ figure is red, the color for priestly vestments worn during the Feast Day of Pentecost. This feast Day is the celebration (memorial) of the event in which the power of the Holy Spirit (traditionally represented as flames, hence the color red for the vestments) descended upon the apostles empowering them with knowledge of, and the ability to speak in, other languages and to teach the new religion of Christianity.

B. Christ's hands: The hands of the Christ figure are held close to one another with three fingers extended, two on the left hand, and one on the right hand, to form a triangle. The triangle is often used within various denominations, especially the Roman Catholic, to represent the Triune God, three in one: the Father, the Son, and the Holy Ghost. While just two fingers form the lateral sides of the triangle, the near forefinger of the left hand suggests a part in the triangular representation of the Triune God.

C. The figures in the background: To the left and to the right of the Christ figure are depictions of the priests of the temple, representing the old church/temple, (the old testament of the Bible), while the central figure of Christ represents the new church/temple (the new testament). The various styles of clothing worn by these figures refer to the various positions held by the temple priests.

D. Title of the painting: Christ Among the Doctors, refers to St. Luke's description in the new testament (Chapter 2 Verses 42,46 , $47,49,50)$ of Christ teaching to the priests in the temple. St. Luke says that Christ was about twelve years old at this time and that it was Christ's first teaching experience. Leonardo's representation of Christ in this painting is that of a very young man, perhaps in his teens.

E. Conclusion: The various forms of Iconography used by Leonardo for this painting direct attention to Christ as a teacher, founder of the new church, and the doctrines as well. Quite possibly, Leonardo conferred with a priest advisor concerning the iconography just as Michelangelo certainly did concerning his frescos for the Sistine Chapel. It is also possible that Leonard visited the Cathedral in Prato to see the fresco of The Feast of Herod, painted by Fra Fillippo in 1452 . In the background of this fresco at the feast table centrally located is a figure wearing the stole of priestly authority within the temple, and of teaching authority. This fresco also juxtaposes the new and old testament, just as Leonardo does in Christ Among the Doctors.

Finally, Christ Among the Doctors is intended as an image concerning teaching, and may have been commissioned by a teaching order within the Church, rather than as a private commission. The facial expressions, and expression of the hands for each priest represented are direct links to St. Luke's statements found in Chapter 2 Verses 46, 47, 49.

John Harrington believes that the Christ figure may well have been painted by Leonardo in support of his application to the Guild of Florentine painters in 1472 .

\section{Perspective and Composition:}

A. Perspective: Leonardo often used one-point perspective in his paintings and drawings, The Last Supper fresco in the refectory of Maria delle Grazie, Milan; The Adoration of the Magi, 1481, Uffizi Gallery, Florence; The Annunciation, 1470, Uffizi, Florence; and the Mona Lisa, 1503, Louvre, Paris are among the more obvious examples. Nearly always, the vanishing point among his onepoint compositions may be located behind the central figure or object. The horizon line on which the single vanishing point is located is placed about one third of the picture planes proportion from the top. This proportion ties in with Leonardo's preference for a strong vertical and horizontal axis. The vertical minor axis and the horizontal may be the axes that hold groups of figures or objects.

B. Composition: When Leonardo uses a single vanishing point perspective, his compositions tend to be symmetrical, lending a certain formality to the overall image. Within the rather formal composition of symmetrical arrangements he activates figures and objects into movement through gesture and placement. When a single figure or groups of figures are used in one of his one-point vanishing point symmetrical compositions depicted from about the waist up to the top of the head, he suggests that it is, in fact, the entire figure, or person who is being represented, implying therefore, a full-length figure portrait. This suggestion of a full-length portrait is accomplished by the relationship of the hands to the bottom of the picture plane (about $1 / 3$ to $1 / 4$ from the bottom), the head with about the same proportional relationship to the top of the picture plane. One may find that throughout all of Leonardo's compositions a mathematical permutation is in play. These are, in effect, compositions that visually read as "right" and "correct", and quite architectural.

Hands as shapes in Leonardo's compositions always play a major role in the success of his compositions but more important than shape within the composition is the hand as a key to understanding the content of the painting or drawing.

Furthermore, hands as Leonardo depicts them are in fact outward manifestations of an inward emotion, thought, or doctrine. The hands of the Christ figure in The Last Supper relay two doctrines, the left hand is extended in an offering of bread symbolizing the consecration of the bread at the sacrifice of the Mass (this is my body), while the right hand is extended in blessing of the wine, or consecration of the wine (this is my blood). The expression, or position of the hand is also the position of the priest's hand in the final blessing at the conclusion of the Mass toward the congregation (go in peace). The hands of the apostles are depicted in a great variety of positions, and placement within the composition, and are quite clearly intended to be outward visual expressions of each apostle's inward emotional and intellectual response to Christ's revelations through hand gestures.

The hand of the Virgin in Leonardos Madonna of the Rocks, 1483 , the Louvre, is extended in blessing over the Christ child, her hand is in the very same position that Leonardo used for his Christ in The Last Supper. For both paintings Leonardo used the triangle as the central geometric shape for each subject, of Christ and the Virgin. The Christ figure in Christ Among the Doctors is also shaped within a centrally located triangle. For each of these paintings, the central triangle is proportionally the larger geometric shape, and is played off against other triangles within the totality of the composition. Leonardo uses the triangle with mathematical permutations that create the underlying architecture of his compo- 


\section{A Protocol for Authentication of Paintings Continued from preceding page}

sitions, thus lending a firm structural whole.

In several of these composition types such as The Mona Lisa, Woman with an Ermine, and Christ Among the DoctorsHarrington, the hand, or hands are used as a visual lead-in to the composition. In each of these compositions the hands may be active, or at rest, but they are, without question, significant symbols in not only understanding Leonardo's genius for composition, but important leads to the content.

C. Conclusion: The perspective, linear and aerial, and composition for Christ Among the Doctors, are directly related to the other Leonardo paintings mentioned, and such, could not be understood by a copyist to the degree of execution in this painting. Further, the perspective and composition for this painting are used by Leonardo to underscore that this painting was indeed a "teaching painting". Leonardo used all his knowledge in mathematical permutations within the compositional and perspective guidelines to support his iconographic information to form an image that was not only a fulfillment of the patron's desires, but was also an early signature work whose visual and intellectual content may be found in other later paintings.

\section{Stylistic Analysis}

Chiaroscuro aside, which is so clearly related to other Leonardo paintings, there appears to be stylistic similarities between Christ Among the Doctors, and other paintings by Leonardo that are important enough to establish this painting as one of Leonardo's.

The hair in this painting is not linearly treated as it is in some of his other paintings, but is more softly brushed with pigment, as it is in the treatment of the hair of the Christ figure in The Last Supper. Christ's hair in The Last Supper is parted off-center, and is parted off-center in Christ Among the Doctors as well. The proportion of the fingers to the body of the hand are greater than one would find normally. This odd proportional preference by Leonardo may be found in his other paintings such as St. John the Baptist, Lady with Ermine, Madonna of the Rocks and the Mona Lisa. This extension of the fingers by about one-fourth more than normal, is certainly intended for expressive purposes. Given the importance Leonardo placed on hands in his compositions it is easy to understand why he stylized the fingers as he did. The lips of the Christ figure in The Last Supper are clearly outlined, and color filled. The Christ Among the Doctors painting reveals that the lips of the Christ figure are treated in the same stylistic manner as are the eyes. The eyes are not on a perfect horizontal, and the nose is long and thin. These facial characteristics may be found in most of Leonardo's representations of the human face. It is rare to find a perfect symmetrical face in his paintings or drawings. Through study of Leonardo's "study sketches" he visually states that no true symmetry exists in nature including the human form, except for mathematical symmetry such as one to one, two to two, etc.

Finally, the light source in most of Leonardo's work is lefthand oriented, that is, the light appears to come from a source that is located to the left of the picture plane. At times, this light source offers very strong light-producing clear cast shadows, or at other times a softly diffused light with cast shadows not clearly defined. Since Leonardo was left-handed, this would be a natural if not automatic choice for a light source.
Christ Among the Doctors reveals a strong light source that comes from the left of the picture plane producing the chiaroscuro effects of light, shade, cast shadow, reflected light, and highlight. Through this lighting mode, the modeling is carried out to the highest degree in order to produce volumes that will give the most convincing illusion of a third dimension. Leonardo focuses the light directly upon the left hand of Christ (this could be a subconscious placement by Leonardo because of his left-handedness, or, a connection to his own spirituality) intending to bring the observer's attention to the hands that form the central triangle of the Christ figure.

Throughout Leonardo's career his use of light in his paintings and drawings is consistent (nearly always left-handed orientation) along with his compositional techniques. It is this very consistency that one finds in Christ Among the Doctors-Harrington. Each one of the visual elements in this painting, if examined separately and placed within the context of any other of his paintings, shows that the transferral would make a perfect fit technically and stylistically.

Stylistically, Leonardo creates a very fine tension between the figures and objects he represents, a tension that one may visually read as a frozen moment in time, but one that never excludes the observer. He brings the observer into the space and activity through his technical ability and force of genius, a space that is always represented as one devoid of sound, a quiet stillness of peace. Christ Among the Doctors exemplifies these qualities, and stands firmly in the place of progression from this early work to later works.

\section{Conclusion}

As of today, there are scholars who do not accept the attribution of Christ Among the Doctors-Harrington to Leonardo. All of those, however, who have made a serious study like Joseph Polizzi, Lanier Graham, Walter McCrone, Klara Garas, Eugene Markowski and, of course, John Harrington are in full agreement that the available evidence fully supports the attribution to Leonardo da Vinci.

This, then, is where IFAR is needed. The owners, John and Elfriede Harrington want nothing more than to share this fine painting with the public by seeing it hanging in a major art museum. Now, however, it can be exhibited only in their home where only they and their friends can enjoy it. IFAR, by a careful and complete study of all past authentication studies and their own added effort, could draw their conclusion with a published paper a decision that like those of the Rembrandt Committee could in time justify an agreement accepted by all parties and thus remove this and other fine paintings from limbo.

\section{References}

1. McCrone, W.C.; Authenticity Study of a Possible Manet Painting; Microscope 1987 35, 173-194.

2. McCrone, W.C., The Shroud of Turin: Blood or Artist's Pigments? Accts. of Chem. Res. 1990 23, 77.

3. McCrone, W.C., L. Graham and Polizzi, J.A., Microscope 1996 44, 119-136.

\section{Postcript}

Several people have recently pointed out the physical resemblance between the three heads of Christ in Christ and the Doctors-Harrington, (top figure), The Last Supper (lower left figure) and the Leonardo painting of Christ from the Brera Museum in Milan (lower center figure). The Christ figure from Christ and the Doctors-Harrington is also shown in the lower right for direct comparison of the three paintings. The close resemblance is very apparent. 

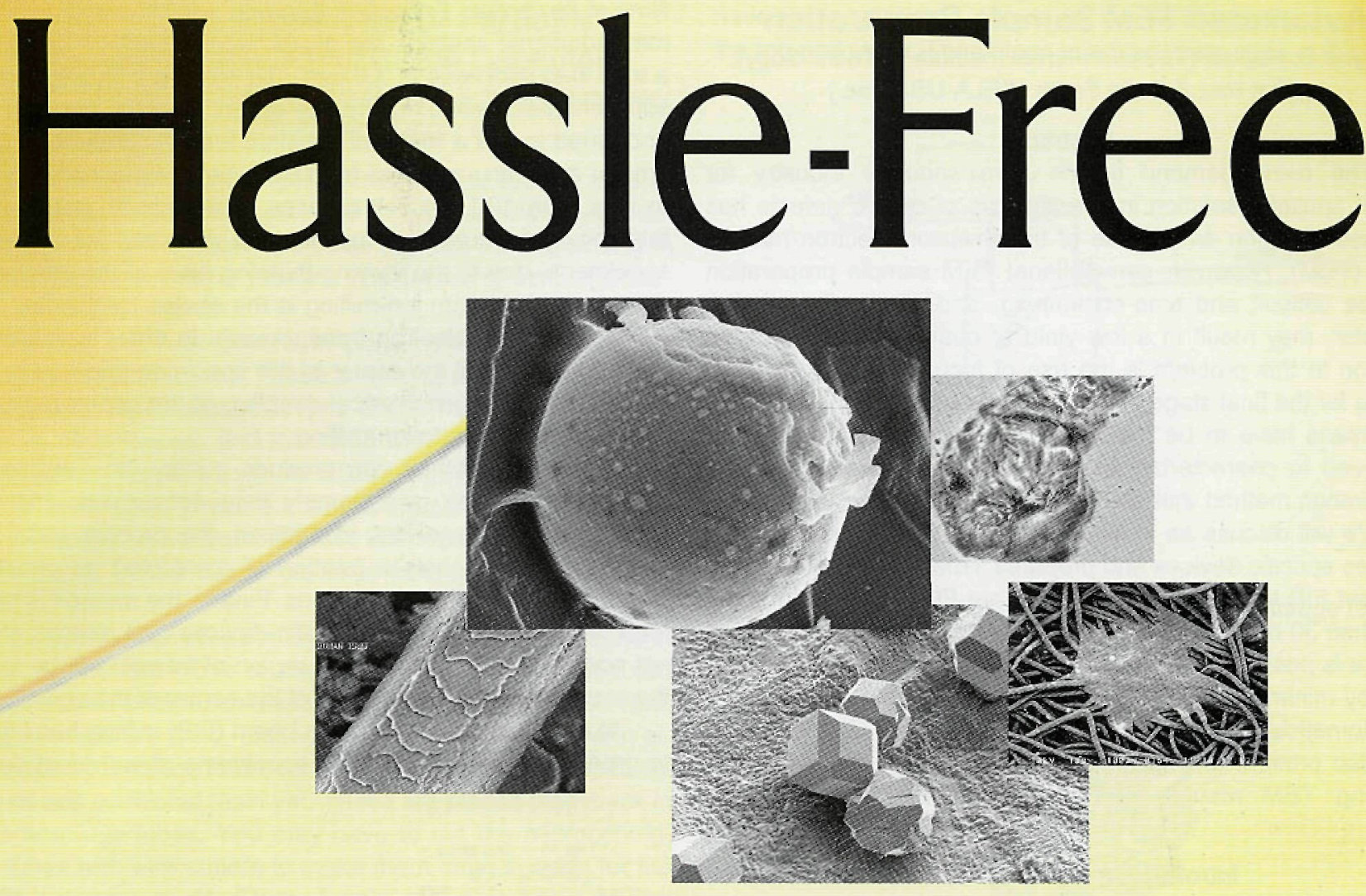

\section{Automated Microanalysis and Microscopy....Just a Click Away}

Announcing the

Personal Automated Feature Analysis System

Looking for comprehensive, no hassle, unattended SEM/EDX analysis. Take a look at the unique

Personal Automated Feature Analysis System (PAFA). A sophisticated software package that enhances the Personal SEM into a highly sophisticated, automated microanalyzer .

Automation for whatever your application

We say

"Personal" because PAFA can be truly customized for a broad spectrum of specific applications. Such as gun shot residue. wear debris, metal inclusion to mention a few. The list is long. Whatever you want analyzed. Particles, features, inclusions, defects and much more, can be done quickly and thoroughly. If you need real time, "live" detection, it's part of the package. The best part. You, personally, no longer have to spend all that time to diligently find all those particles. Customized reports are given with all the critical information you need. All easily, unattended and with no hassles.

\section{No company does microanalysis automation better}

Why do we do it better? It's simple. Every component, the SEM, EDX, stage control, the software, is from one source-R J Lee Instruments, a microanalysis expertise that is unsurpassed. No integrating problems, no finger pointing from one manufacturer to another, and yes, no hassles. If there ever is a problem, you have a single source supplier and guarantee-R J Lee Instruments.

Take a closer look at hassle-free automation today. Call 1-800 538-6850 or visit our website www.rjleeinst.com. 